\title{
Accuracy of memory of male and female eyewitnesses to a criminal assault and rape
}

\author{
A. DANIEL YARMEY and HAZEL P. TRESSILLIAN JONES \\ University of Guelph, Guelph, Ontario NIG 2W1, Canada
}

\begin{abstract}
Male and female subjects observed a slide presentation of a sexual assault and implied rape. Following recall and identification tests, subjects completed an attitudes-toward-rape questionnaire. No differences were found in free recall, interrogatory recall for details of the crime, and identifications of either the suspect or victim by males and females. Similarly, no differences were found in memory between subjects categorized as strong or weak in antirape attitudes. Females made more false negative identifications of the suspect. That is, women more frequently reported that the suspect was not in the lineup when in fact he was. Males and subjects holding strong antirape attitudes were reliably more certain in their identification of the suspect and victim. However, certainty of identification was not related to accuracy of identification.
\end{abstract}

In the last few years, increased scientific attention has been directed by researchers and theorists toward the phenomenon of rape. Rape is a unique crime insofar as the women who are the targets of the assault may not be perceived with compassion, but instead, may be assigned responsibility for their victimization (Amir, 1971; Curtis, 1974). Most research on this crime has focused on causal attributions and general attitudes of the public and other groups toward rape (see, for example, Feild, 1978; Krulewitz \& Payne, 1978). In the present investigation, we were concerned with determining whether male and female bystander eyewitnesses would differ in their memory for details of a criminal assault and rape. A second purpose of this study was to investigate whether witnesses categorized as strong or weak in antirape attitudes would differ in their accuracy of eyewitness memory, and in their subjective certainty of correctness in their testimony.

Observers selectively attend to events and interpret them in ways that are consistent with their expectations and attitudes (Massad, Hubbard, \& Newtson, 1979). Also, observers assign attributions of intent that further guide their perceptions and recall of behavior (Zadny $\&$ Gerard, 1974). These attributions may be of particular importance when the event witnessed is of such a nature that witnesses are likely to hold strong emotional attitudes in relation to it. In cases of sexual assault, preconceptions of assailant and victim characteristics may be important determinants of a witness' memory and evaluation of the event (Yarmey, Jones, \& Rashid, 1983). Whether or not attitudinal predisposi-

This research was supported by a grant from the Social Sciences and Humanities Research Council of Canada. Reprint requests should be addressed to Dan Yarmey, Department of Psychology, University of Guelph, Guelph, Ontario N1G 2W1, Canada. tions to the act of rape influence eyewitness memory, however, remains to be determined.

Individual differences of the sex of witnesses have received limited attention from eyewitness researchers. Clifford and Scott (1978) showed that males and females were equally accurate in recalling details of a nonviolent incident, but males were superior in recall of details of a violent event. Powers, Andriks, and Loftus (1979) found that women were more accurate in remembering female-oriented details of a crime (e.g., women's clothing), but men were more accurate in recall of maleoriented details (e.g., details about a male thief's appearance). Kuehn (1974) observed in a field study that female victims were less complete than male victims in verbal descriptions of assailants. Although the above three studies suggest differential performance between the sexes in eyewitness memory, the general literature on sex differences for facial recognition and accuracy of recall for criminal details has been equivocal. Some studies have shown that females are superior to males (e.g., Ellis, Shepherd, \& Bruce, 1973; Going \& Read, 1974; Lipton, 1977; Yarmey, 1974; Yarmey \& Johnson, 1982), others have found males better in identifying male faces and females superior in remembering female faces (Witryol \& Kaess, 1957), and still others have failed to find any reliable differences between the sexes (e.g., McKelvie, 1978; Laughery \& Fowler, Note 1).

In the present study, differential memory performance between men and women could occur if female witnesses were to identify with and attend to the female victim. It was not expected, however, that men would automatically identify with a rapist. Nevertheless, the apparent conflicting results of witness sex in the eyewitness research literature prevented our making a strong hypothesis.

As stated previously, attitudes toward rape have been shown to be related to attributions of responsibility. 
This, together with the fact that people preferentially attend to and recall information consistent with their interests, attitudes, and beliefs, led us to hypothesize that witnesses who are more sympathetic to rape victims and hold stronger antirape attitudes may differ in memory performance from witnesses who have weaker antirape attitudes.

\section{METHOD}

\section{Subjects}

A total of 24 males and 24 females ranging in age from 16 to 44 years (mean $=20.8$ years) participated as subjects in this experiment.

\section{Procedure}

The experiment was divided into five stages: (1) viewing the assault, (2) free recall test, (3) interrogatory report, (4) identification tests, and (5) completion of an attitudes-toward-rape scale.

(1) Viewing the assault: a sequence of 60 color slides depicting an assault and implied rape in a park was shown. Each slide was presented for $2 \mathrm{sec}$ unaccompanied by any voice narration. The total viewing time was $120 \mathrm{sec}$, with the victim seen for $81 \mathrm{sec}$, the assailant for $68 \mathrm{sec}$, and other environmental information for $22 \mathrm{sec}$. Both the rapist and the victim were seen from front, profile, and back views. The rapist projected an unpleasant or tough demeanor and was dressed in a red T-shirt, black leather jacket, and blue jeans. The victim was considered an attractive but unprovocative woman and was dressed in a conventional skirt and blouse.

(2) Free recall: subjects were instructed to write down as many details as they could remember about the event they had just witnessed.

(3) Interrogatory recall: a 30-item multiple-choice questionnaire consisting of 10 questions each on the rapist, the victim, and the environment was given. Each question was a declarative statement requiring a word or a phrase to be completed. For example, one question was "The victim was wearing: (a) brown dress shoes; (b) no shoes; (c) white running shoes; (d) black dress shoes; (e) don't know."

(4) Identification tests: subjects were asked to identify the assailant, followed by an identification test for the victim. Two nine-person full-face color photo lineups were used for both targets. The photographs did not reveal any clothing. Subjects were given in counterbalanced order a lineup containing the target and a lineup with the target absent. Witnesses were told that the suspect's (victim's) picture might or might not be in the lineups. Three types of identification responses were permitted: (a) "Suspect [victim] is number ..."; (b) "suspect [victim] is not in the lineup"; (c) I don't know." In addition, subjects stated how certain they were of each decision on a 4-point scale, ranging from "I am guessing" to "I am sure enough to testify in court." Participants paced themselves and took as much time as they needed to make each response.

(5) Attitudes-toward-rape scale: A 21-item questionnaire (Thornton, Robbins, \& Johnson, 1981) was the final dependent measure. The scale is composed of statements reflecting commonly held beliefs or opinions about rape, rapists, and rape victims. For each item, the witness indicated his or her extent of agreement or disagreement using Likert-type responses. Some of the items included in the scale are: "Nice' women do not get raped." "In most cases, when a woman was raped, she was asking for it." "Women provoke rape by their appearance or behavior."

\section{RESULTS}

A median split of scores of subjects' attitudes toward rape yielded a group holding strong antirape attitudes and a group holding weak antirape attitudes. Males and females were evenly distributed in both groups, with 11 males and 13 females classified in the strong antirape category and 13 males and 11 females in the weak antirape category.

\section{Free Recall}

Thirty-three identifiable characteristics describing each of the suspect, the victim, and the environment were catalogued by the experimenters. Subjects recalled $29 \%$ of all descriptions. Approximately $1 \%-2 \%$ of all free recall descriptions were inaccurate, and errors were made equally to the assailant, victim, and environment. The analyses failed to reveal any reliable differences between male and female subjects in their free reports of suspect characteristics, victim characteristics, or environmental features. Also, attitudes toward rape failed to be predictive for any measure of free recall accuracy.

\section{Interrogatory Recall}

Subjects were correct on the average on $52 \%$ of the multiple-choice questions. There were no reliable recall differences between males and females, or between subjects differing in their attitudes toward rape.

\section{Identifications}

The proportions of hits, false alarms, "don't knows," "not there" (false negatives), and correct rejections for the identification of the suspect and victim, in both the target-present lineup and the target-absent lineup as a function of the sex of the witnesses and as a function of the subjects' attitudes toward rape, are presented in Tables 1 and 2 . Inspection of both tables reveals that witnesses were able to identify the suspect and the victim approximately at the level of chance $(11 \%)$. False identification of foils generally exceeded the recognition of the suspect and the victim. Even in the target-absent lineups, witnesses generally gave more false alarms than "don't know" responses.

The only significant difference between male and female witnesses was the substantially greater tendency for females to make false negative errors in identification of the suspect $\left[\chi^{2}(3)=8.24, p<.05\right]$. Females, more so than males, stated that the suspect was not present in the lineup when in fact he was. None of the other comparisons between males and females was significantly different. Similarly, none of the comparisons between witnesses who held strong and weak antirape attitudes was reliably different.

An analysis of confidence ratings associated with the identification of the assailant and the victim showed that males were significantly more confident in their choices than were females $[F(1,42)=6.38, p<.01]$. Since hit scores were low, it is not surprising that there was no correlation between accuracy of performance and certainty of responses for either males or females, nor between witnesses having strong and weak antirape 
Table 1

Proportion of Identifications of the Suspect and the Victim as a Function of Sex of Witnesses

\begin{tabular}{|c|c|c|c|c|c|c|c|}
\hline \multirow{3}{*}{$\begin{array}{c}\text { Target } \\
\text { Witnesses }\end{array}$} & \multicolumn{4}{|c|}{ Target-Present Lineup } & \multicolumn{3}{|c|}{ Target-Absent Lineup } \\
\hline & \multirow[b]{2}{*}{ Hits } & \multicolumn{3}{|c|}{ Responses } & \multirow{2}{*}{$\begin{array}{c}\text { Correct } \\
\text { Rejections }\end{array}$} & \multirow{2}{*}{$\begin{array}{c}\text { False } \\
\text { Alarms }\end{array}$} & \multirow{2}{*}{$\begin{array}{l}\text { Don't } \\
\text { Know }\end{array}$} \\
\hline & & False Alarms & Don't Know & Not There & & & \\
\hline \multicolumn{8}{|c|}{ Target: Suspect } \\
\hline Males & 8 & 33 & 13 & 46 & 71 & 17 & 12 \\
\hline Females & 4 & 13 & 0 & 83 & 54 & 33 & 13 \\
\hline \multicolumn{8}{|c|}{ Target: Victim } \\
\hline Males & 21 & 25 & 8 & 46 & 58 & 25 & 17 \\
\hline Females & 17 & 17 & 4 & 62 & 71 & 12 & 17 \\
\hline
\end{tabular}

Table 2

Proportion of Identifications of the Suspect and the Victim as a Function of Witnesses' Attitudes Toward Rape

\begin{tabular}{|c|c|c|c|c|c|c|c|}
\hline \multirow{3}{*}{$\begin{array}{l}\text { Antirape } \\
\text { Attitude } \\
\end{array}$} & \multicolumn{4}{|c|}{ Target-Present Lineup } & \multicolumn{3}{|c|}{ Target-Absent Lineup } \\
\hline & \multirow[b]{2}{*}{ Hits } & \multicolumn{3}{|c|}{ Responses } & \multirow{2}{*}{$\begin{array}{c}\text { Correct } \\
\text { Rejections }\end{array}$} & \multirow{2}{*}{$\begin{array}{c}\text { False } \\
\text { Alarms }\end{array}$} & \multirow{2}{*}{$\begin{array}{l}\text { Don't } \\
\text { Know }\end{array}$} \\
\hline & & False Alarms & Don't Know & Not There & & & \\
\hline \multicolumn{8}{|c|}{ Target: Suspect } \\
\hline Strong & 4 & 17 & 12 & 67 & 54 & 29 & 17 \\
\hline Weak & 8 & 29 & 0 & 63 & 71 & 21 & 8 \\
\hline \multicolumn{8}{|c|}{ Target: Victim } \\
\hline Strong & 12 & 17 & 8 & 63 & 58 & 17 & 25 \\
\hline Weak & 25 & 25 & 4 & 46 & 71 & 21 & 8 \\
\hline
\end{tabular}

attitudes. However, an interesting difference was found between subjects holding different attitudes toward rape in terms of their subjective confidence. Strong antirape witnesses were significantly more certain about their identifications than were weak antirape subjects $[F(1,46)=11.54, p<.001]$, although as previously stated they did not differ in actual performance.

\section{DISCUSSION}

The major results of this investigation may be summarized as follows. Male and female bystander witnesses to a slide projection of a criminal assault and implied rape did not differ in free verbal recall, interrogatory recall, or in identification of either the suspect or the victim. Similarly, subjects categorized as having strong antirape attitudes did not differ in accuracy of eyewitness memory from subjects categorized as having weak antirape attitudes. The only difference in identification performance between male and female witnesses was the greater tendency for women to report that the suspect was not in the photo lineup, when in fact he was. Males were reliably more certain of their identifications than were females. Similarly, witnesses who held strong antirape attitudes were reliably more positive of the correctness of their identifications than were weak antirape witnesses. However, neither males nor strong antirape witnesses were superior in their memorial performance.

The failure to find reliable differences between the sexes in eyewitness memory for a criminal assault and rape does not minimize the positive findings of differential performance discovered by other researchers such as Powers et al. (1979). It is possible that the criminal assault and rape scenario was equally salient to males and females. Also, female witnesses, including those categorized as holding strong antirape attitudes, may have found the victimization of the woman so distressing that they did not identify with or overly attend to her. Men and women may attend to and remember different types of items in a crime, as Powers et al. suggest, but this will be true only if there is differential attraction and selective attention to those details. Yarmey (1979) concluded that "in the case of recognition memory for faces differences in accuracy seem to lean toward females over males, but the differences in absolute percentage scores are very small and have little practical importance" (p. 127). We feel that this conclusion should be amended. Sex differences in accuracy of eyewitness memory will probably be small, but their practical importance depends upon their usefulness to police, lawyers, judges, and others who want to reconstruct the events of the past. Investigators attempting to determine what happened must consider individual factors such as the interest, orientations, and attributions of responsibility of a witness. These factors may relate to the quality of his or her eyewitness report.

The finding that males and persons holding strong antirape attitudes were significantly more confident in their ability to identify the suspect and the victim supports the contention that individual differences and social characteristics influence at least some aspects of eyewitness performance. Obviously, this should be of concern to the police in terms of their evaluation of the credibility of potential witnesses, as well as influencing the direction of their criminal investigations.

\section{REFERENCE NOTE}

1. Laughery, K. R., \& Fowler, R. H. Factors affecting facial recognition (Report No. UHMUG-3). Houston: University of Houston Mug File Project, 1977.

\section{REFERENCES}

Amir, M. Patterns in forcible rape. Chicago: University of Chicago Press, 1971. 
Clifford, B. R., \& Scotr, J. Individual and situational factors in eyewitness testimony. Journal of Applied Psychology, 1978, 63, 352-359.

Curtis, L. A. Victim precipitation and violent crime. Social Problems, 1974, 21, 594-605.

Ellis, H., Shepherd, J., \& Bruce, A. The effect of age and sex upon adolescents' recognition of faces. Journal of Genetic Psychology, 1973, 123, 173-174.

Ferld, H. S. Attitudes toward rape: A comparative analysis of police, rapists, crisis counselors, and citizens. Journal of Personality and Social Psychology, 1978, 36, 156-179.

Going, M., \& READ, J. D. Effects of uniqueness, sex of subject, and sex of photograph on facial recognition. Perceptual and Motor Skills, 1974, 39, 109-110.

Krulewitz, J. E., \& Payne, E. J. Attributions about rape: Effects of rapist force, observer sex and sex role attitudes. Journal of Applied Social Psychology, 1978, 8, 291-305.

Kuehn, L. L. Looking down a gun barrel: Person perception and violent crime. Perceptual and Motor Skills, 1974, 39, 1159-1164.

LIPTON, J. P. On the psychology of eyewitness testimony. Journal of Applied Psychology, 1977, 62, 90-95.

Massad, C. M., Hubbard, M., \& Newtson, D. Selective perception of events. Journal of Experimental Social Psychology, 1979, 15, 513-532.

McKelvie, S. J. Sex differences in facial memory. In M. M. Gruneberg, P. E. Morris, \& R. N. Sykes (Eds.), Practical aspects of memory. New York: Academic Press, 1978.
Powers, P. A., Andriks, J. L., \& Loftus, E. F. Eyewitness accounts of females and males. Journal of Applied Psychology, $1979,64,339-347$.

Thornton, B., Robbins, M. A., \& Johnson, J. A. Social perception of the rape victim's culpability: The influence of respondents' personal-environmental causal attribution tendencies. Human Relations, 1981, 34, 225-237.

WITRYOL, S., \& KAEss, W. Sex differences in social memory tasks. Journal of Abnormal and Social Psychology, 1957, 54, 343-346.

YARMEY, A. D. Proactive interference in short-term retention of human faces. Canadian Journal of Psychology, 1974, 28, 333338.

YARMEY, A. D. The psychology of eyewitness testimony. New York: Free Press, 1979.

YARMEY, A. D., \& Johnson, J. Evidence for the self as an imaginal prototype. Journal of Research in Personality, 1982, 16, 238-246.

YarmeY, A. D., Jones, H. P. T., \& RAshid, S. Eyewitness memory of elderly and young adults. In D. J. Müller, D. E. Blackman, \& A. J. Chapman (Eds.), Topics in psychology and law. Chichester, England: Wiley, 1983.

ZadNy, J., \& Gerard, H. B. Attributed intentions and informational selectivity. Journal of Experimental Social Psychology, 1974, 10, 34-52.

(Received for publication January 5, 1983.) 